\title{
Sex differences in social influence: Social learning
}

\author{
ROBERT FRANK WEISS, JOYCE JETTINGHOFF WEISS, \\ V. L. WENNINGER, and SUSAN SICLARI BALLING \\ University of Oklahoma, Norman, Oklahoma 73019
}

\begin{abstract}
Sex differences in social influenceability were notable for their absence in 28 social learning experiments in which sex difference data were previously unreported or unreviewed. Competition, altruism, and dyadic communication were the three substantive research areas examined. Analysis emphasized the role of repeated social influence attempts, of novel conceptions and manipulations of motivation and reward, and of realms of experimental law in which the underlying simplicity is integral and the integration is theoretical.
\end{abstract}

Social psychology will be much the better for Eagly's (1978) demonstration of the paucity of evidence and doubtful reasoning that underlie the views on sex differences in social influenceability still fashionable among social psychologists. Together with Dabbs' (1977) trenchent admonitory note, Eagly's review should serve to free social psychology from a certain amount of prejudicial nonsense masquerading as science. Since it would have been quite impossible for Eagly's review to be exhaustive, it constitutes an open invitation to those of us whose interests would not have led us to attempt such an extensive review to make available aspects of our own research that may now serve as a useful supplement to the Eagly review. In our case, this open invitation is rather poignant, since Eagly's criticism of reliance on popular belief in place of science is quite narrowly aimed at the sex difference question. Not to put too fine a point on it, reliance on popular belief commonly substitutes for scientific theory in social psychology, and this substitution is doubtless one of the proximate factors responsible for the retrograde state of social psychology as compared with, say, experimental psychology or physics. All the research reviewed here was guided by rather formal explicit theory in which sex of subject was not a variable of theoretical interest and which, therefore, made no prediction of sex differences in influenceability. A proper concern for the generality of theoretical principles led us to examine the data for sex difference effects. Our methodology thereby protected us from falling victim to "popular beliefs about how the sexes differ" (Eagly, 1978, p. 108) and from any neglect of sex differences that might, in fact, be found.

\section{SCOPE}

The social influence research reviewed here encompasses three different substantive areas of social psy-

Requests for reprints should be addressed to Robert Frank Weiss, Department of Psychology, University of Oklahoma, Norman, Oklahoma 73019. chology: altruism, competition, and communication. This diversity of substantive research area, combined with similarity of theoretical approach, permits both breadth and brevity. Thorough expositions of experimental methodology and of the several formal theories are available in the published reports, and we will not require a full recapitulation here. Since the published research is not primarily concerned with sex differences, this article not only reviews but also, in several instances, provides the first report of sex difference results.

\section{SOCIAL INFLUENCE THROUGH ALTRUISTIC REINFORCEMENT}

People will learn an instrumental response the reinforcement for which is the deliverance of another human being from suffering. Six experiments show regular acquisition curves of increasing instrumental response speed over trials. The instrumental response being influenced by this altruistic reinforcement was a simple button-pressing response: The social content was in the motivation induced by the other person's suffering and in the altruistic reinforcement. There were no sex differences in the amount learned or in the rate of learning for altruistic reinforcement over the course of trials. Popular belief affords any number of "reasons" for expecting results that repeatedly did not occur: Women are overly emotional or, alternatively, more humanely sensitive to the suffering of others, whereas men are callous or, alternatively, repositories of heroic virtue and hence quick to come to the rescue.

Insofar as such popular beliefs might charitably be regarded as a rudimentary form of theory, we would be well advised to observe standard scientific practice in which a theory is replaced by a better theory, rather than simplistically disproved. The formal development of the theory of altruistic reinforcement provides such social analogues of learning variables as magnitude of altruistic reinforcement, delay of altruistic reinforcement, partial altruistic reinforcement, and intermittent arousal of altruistic drive, as well as number of acquisition trials. Each of these variables was experimentally 
shown to have the effects predicted from the formal theory. Such a configuration of predicted results is not so easily forthcoming from popular belief as from scientific theory. There were no sex differences in the effects of any of the social variables and no main effect of sex in any of the six experiments.

Much interest has been shown in the question of how socially constructive or altruistic instrumental behavior can be learned and maintained through extrinsic rewards. These six experiments demonstrated that the roots of altruistic behavior are so deep that people not only help others but also find it rewarding to do so. Men and women equally manifest this admirable and encouraging characteristic (Weiss, Boyer, Lombardo, \& Stich, 1973; Weiss, Buchanan, Altstatt, \& Lombardo, 1971; Weiss, Cecil, \& Frank, 1973).

\section{SOCIAL INFLUENCE THROUGH COMPETITIVE MOTIVATION}

Studying the motivational properties of competition, rather than examining competitive behavior as a dependent variable, revealed that competition induces a noxious drive and that people will learn an instrumental response the reinforcement for which is the termination of competition. Seven experiments show regular acquisition curves of increasing instrumental response speed over trials. The instrumental response being influenced by this competitive motivation was a simple switchthrowing response: The social content was in the aversive motivation induced by competition and in the reinforcement provided by the cessation of competition. There were no sex differences in the amount learned or in the rate of learning over the course of trials. Popular belief about the sexes combines with popular belief about social class to provide a rich brew of "reasons" for expecting results that never did occur: Illustratively, men are aggressively competitive, whereas women are yielding (on which, see Eagly, 1978). Male competitiveness is, with painful naivete, often seen in terms of a competition for career advancement that is universal in our society, for all the world as if no one works on an assembly line. More sophisticated and intriguing problems are likely to escape consideration altogether: Extreme forms of competitive piecework and exploitation of female labor both flourish where free trade unions are proscribed, as in the notorious case of Sovietbloc Stakhanovism or South .Korean sweatshops. Another intriguing problem is raised in Eagly's review of experimental game research, in which there is some evidence of female preference for egalitarian and noncompetitive conduct. This point nicely brings out one of the distinctively interesting aspects of the present research, since we investigate the motivational properties of competition rather than examining competitive behavior as a dependent variable. Even if men do more commonly engage in competitive behavior, the experience is not necessarily pleasant, just as men do have a greater frequency of heart attacks but do not necessarily find the experience pleasant. The complexities of the problem may thus be similar to "the neurotic paradox" and self-punitive behavior generally. The present experiments are particularly suitable for bringing out the simplicities of competitive motivation in social influence, and the absence of any sex differences in these very well replicated acquisition effects speaks clearly to this point.

The simplicities of competitive motivation in social influence, brought out in these experiments, were not limited to acquisition effects. The formal development of the theory of competitive motivation provides such social analogues of learning variables as delay of the reinforcing termination of competition, magnitude of the reinforcing termination of competition, partial reinforcement schedules of the termination of competition, intermittent arousal of competitive drive, intensity of competitive drive varied by prior experience of task competence, and intensity of competitive drive varied by number of competitive opponents. Each of these variables was experimentally shown to have the effects predicted from the formal theory. There were no sex differences in the effects of any of the social variables and no main effect of sex in any of the seven experiments. The simplicity revealed in this research is something more than the accumulation of compatible facts. It is an integral simplicity, and the integration is accomplished by means of the theory that predicts and explains these facts (Steigleder, Weiss, Balling, Wenninger, \& Lombardo, 1980; Steigleder, Weiss, Cramer, \& Feinberg, 1978).

\section{SOCIAL INFLUENCE IN DYADIC COMMUNICATION}

People will learn an instrumental response the reinforcement for which is the opportunity to speak in reply to a person of differing opinion. The instrumental response being influenced by this social reinforcement was a simple switch-throwing response: The social content was in the motivation induced by the other person's differing opinion (Byrne, 1971; Wicklund \& Brehm, 1976) and in the reinforcing function of speaking in reply. Experimental demonstration of our formal theoretical analogies extends well beyond the analogues of acquisition and extinction, commonly deemed sufficient in social psychology or behavior therapy, to include analogues of partial reinforcement effects, intermittent arousal of drive effects, delay of reinforcement effects, drive effects, correlated reinforcement effects (discrete-trials DRL), and correlated delay of reinforcement effects. Illustratively, if speaking in reply has the functional properties of reinforcement, then the time interval between an instrumental response and the reinforcing reply should have the functional properties of delay of reinforcement. Our results include a perfectly monotonic 6-point delay of reinforcement gradient that would arouse envy in the heart of any rat 
runner. In 15 well replicated experiments, we found no sex differences in the effects of any of the social variables and no main effect of sex. The opportunity to speak in reply plays a functional role in interpersonal communication, commensurate in significance with its status as a basic structural difference between the monologue of mass communication and the dialogue of personal conversation.

The social significance and theoretical elegance of this research contrasts acutely with notions based on popular beliefs about how the sexes differ. Descending easily to the ridiculous, we may imagine our strong, silent Oklahoma cowboys sitting tongue-tied, unable to reply, while the chatterbox womenfolk carry on at great length and to great effect on the instrumental response. More plausible versions of female influenceability through female verbal ability are effectively analyzed by Eagly (1978). It would not be ridiculous to entertain the idea that consistent group differences in verbal ability could affect the reinforcing value of speaking in reply, and we checked for verbal ability effects directly. After all, there is a greater range of verbal ability scores within each sex than there is between the sexes, just as there is a greater range of IQ scores within each race than there is between the races (see, e.g., Weiss, Boyer, Colwick, \& Moran, 1971; Weiss, Lombardo, Warren, \& Kelley, 1971; Weiss, Steigleder, Cramer, \& Feinberg, 1977).

\section{SEX OF SUBJECT AND SEX OF GROUP}

As the gentle reader will recall, all the research reviewed here was guided by rather formal explicit theory in which sex of subject was not a variable of theoretical interest. In pursuit of clear-cut experimental tests of theory, we employed the familiar technique of same-sex pairs. When sex differences are found in such same-sex groups, "a subject may be displaying a sexrelated response characteristic or responding to sexrelated stimulus characteristics of other members of the group" (Dabbs, 1977, p. 343). No sex differences were found. "To assume that sex of subject is more important than sex of partner reflects unwarranted bias on the part of the researcher" (Dabbs, 1977, p. 343). After all, prejudice depends in some measure upon the availability of discriminable stimulus characteristics of out-group members, such as skin color, hooked noses, Irish brogues, or secondary sexual characteristics.

\section{DISCUSSION}

Three distinctive characteristics of this research are of interest to our present inquiry.

\section{Acquisition Trials}

All 28 experiments assessed the gradual development of social influence effects across a series of trials. The logic of most social influence research requires only the usual beforeand-after design or an influence attempt followed by measurement. The present research shows no sex differences appearing or disappearing with repeated and continuingly effective influence attempts.

\section{Sources of Motivation and Reward}

In a learning-theoretical treatment, we might expect to find altruism, competition, and speaking in reply treated as social behaviors to be learned for some reinforcement such as social approval, M\&M candy, or children's toys. Instead, we have inverted the perspective, theoretically and experimentally. Thus, altruism is rewarding, and speaking in reply is no longer the familiar dependent variable of clinical interview research, but, rather, the reinforcement that influences an instrumental response. We have seen that these nontraditional sources of motivation and reinforcement can be diverted from their normal functions and converted into resources in service of the learning of new behavior in such a manner as to encompass diverse substantive areas of social psychology and people of both sexes with encouraging consistency and elegance.

\section{The Problem of Popular Beliefs}

"We should try to resist a natural tendency to assume that the subject behaves in a certain way because he or she is a certain kind of person. As researchers, we appear to overemphasize personal attributes of the subject, showing the same tendency that biases naive observers" (Dabbs, 1977, p. 344). "This bias might be understood if we assume that psychologists, like naive observers, derive from every day life beliefs that men and women differ strongly on dimensions of influenceability" (Eagly, 1978, p. 108). Remedies for this naivete are provided by Dabbs' ingenious experimental designs and Eagly's convincing demonstration of scholarly "skepticism concerning scientific generalizations that may be a product of popular beliefs about how the sexes differ" (Eagly, 1978, p. 108). We have sought to demonstrate that the skillful use of theory can bring further gains in sophistication. As an explanatory concept, sex of subject is ineffectual, a calculus that does not calculate, as few would seriously dispute. Psychologists may seek to endow the concept with the predictive and explanatory power of fact or theory. In science, theories normally are not mere formalizations of popular beliefs but, rather, depart radically from such beliefs by taking their rise in such processes as retroductive reasoning from surprising patterns of research data or analogical reasoning that precisely relates, say, altrusim to such unlikely models as reinforcement laws in instrumental conditioning.

\section{REFERENCES}

Byrne, D. The attraction paradigm. New York: Academic Press, 1971.

DABBs, J. M., JR. Does reaction to crowding depend upon sex of subject or sex of subject's partners? Journal of Personality and Social Psychology, 1977, 35, 343-344.

Eagly, A. H. Sex differences in influenceability. Psychological Bulletin, 1978, 85, 86-116.

Steigleder, M. K., Weiss, R. F., Balling, S. S., Wennimger, V. L., \& Lombardo, J. P. Drive-like motivational properties of competitive behavior. Journal of Personality and Social Psychology, 1980, 38, 93-104.

Steigleder, M. K., Weiss, R. F., Cramer, R. E., \& Feinberg, R. A. Motivating and reinforcing functions of competitive behavior. Journal of Personality and Social Psychology, 1978, 36, 1291-1301.

Weiss, R. F., Boyer, J. L., Colwick, J. T., \& Moran D. J. A delay of reinforcement gradient and correlated reinforcement in the instrumental conditioning of conversational behavior. Journal of Experimental Psychology, 1971, 90, 33-38.

Weiss, R. F., Boyer, J. L., Lombardo, J. P., \& Stich, M. H. Altruistic drive and altruistic reinforcement. Journal of Personality and Social Psychology, 1973, 25, 390-400. 
Weiss, R. F., Buchanan, W., Altstatt, L., \& Lombardo, J. P. Altruism is rewarding. Science, 1971, 171, 1262-1263.

Weiss, R. F., Cecil, J. S., \& Frank, M. J. Steep delay of reinforcement gradient in escape conditioning with altruistic reinforcement. Bulletin of the Psychonomic Society, 1973, 2, 372-374.

Weiss, R. F., Lombardo, J. P., Warren, D. R., \& Kelley, K. A. The reinforcing effects of speaking in reply. Journal of Personality and Social Psychology, 1971, 20, 186-199.
Weiss, R. F., Steigleder, M. K., Cramer, R. E., \& Feinberg, R. A. Delay of reinforcement and delay shifts in dyadic communication. Bulletin of the Psychonomic Society, 1977, 9, 193-196.

Wicklund, R. A., \& Brehm, J. W. Perspectives on cognitive dissonance. Hillsdale, N.J: Erlbaum, 1976.

(Received for publication September 2, 1981.) 